\title{
Comparative Study of Unilateral Axillo-Breast Approach with Gas Insufflation Versus Gasless Transaxillary Approach for Endoscopic Thyroidectomy in a Single Institute
}

\author{
Ik Joon Choi, Nam Young Kim, Kyoung Hun Kim, \\ Byeong-Cheol Lee, Guk-Haeng Lee, and Myung-Chul Lee \\ Department of Otorhinolaryngology-Head and Neck Surgery, Korea Cancer Center Hospital, Korea Institute of Radiological and \\ Medical Sciences (KIRAMS), Seoul, Korea
}

\section{내시경갑상선절제술을 위한 가스 주입식 일측 액와-유방 접근법과 무가스 경액와부 접근법의 단일기관 비교연구}

최익준 · 김남영 · 김경헌 · 이병철 · 이국행 · 이명철

한국원자력의학원 원자력병원 이비인후-두경부외과

\author{
Received October 15, 2016 \\ Revised November 16, 2016 \\ Accepted November 23, 2016 \\ Address for correspondence \\ Myung-Chul Lee, MD, PhD \\ Department of Otorhinolaryngology- \\ Head and Neck Surgery, \\ Korea Cancer Center Hospital, \\ Korea Institute of Radiological and \\ Medical Sciences (KIRAMS), \\ 75 Nowon-ro, Nowon-gu, \\ Seoul 01812, Korea \\ Tel $+82-2-970-2173$ \\ Fax $+82-2-970-2450$ \\ E-mail Lmc@daum.net
}

\begin{abstract}
Background and Objectives There have been various approaches introduced for endoscopic thyroidectomy. This study evaluates and compares the surgical outcomes of two such approaches: the unilateral axillo-breast approach (UABA) with gas and the gasless transaxillary approach (TA).

Subjects and Method We retrospectively analyzed 279 patients who underwent endoscopic thyroidectomy via UABA with gas or gasless TA from March 2008 to August 2012. Studied variables were clinicopathologic data, surgical outcomes, complications, and cosmetic satisfactions.

Results Of the 279 patients, 195 (69.9\%) underwent UABA with gas and 84 (30.1\%) underwent gasless TA. All of the variables related to clinicopathologic characteristics showed no significant differences between the two groups. The mean operation time was significantly shorter in the UABA with gas group $(131.76 \pm 44.37 \mathrm{~min})$ than in the gasless TA group (191.01 \pm $55.90 \mathrm{~min})(p<0.001)$. The mean postoperative pain Visual Analogue Scale scores in the UABA with gas group were $2.61 \pm 0.96$ and $1.85 \pm 0.79$, respectively, and those in the gasless TA group were $3.12 \pm 1.02$ and $2.17 \pm 0.76$, respectively, at 1 and 3 days after surgery. Incidences of postoperative complications were similar except for the higher rate of seroma in the gasless TA group. Cosmetic satisfaction scores of UABA with gas were higher than those of the gasless TA.

Conclusion UABA with gas may be a good option for endoscopic thyroidectomy because this approach is less invasive than the gasless TA is.

Korean J Otorhinolaryngol-Head Neck Surg 2016;59(12):848-55

Key Words Endoscopy · Surgery · Thyroidectomy.
\end{abstract}

\section{Introduction}

Since the introduction of endoscopic parathyroidectomy by Gagner ${ }^{1)}$ in 1996 and endoscopic thyroidectomy by Hüscher, et al. ${ }^{2}$ in 1997, various endoscopic techniques have been developed for thyroid surgery. These include the cervi- 
cal, anterior chest wall, breast, and axillary approaches, as well as their combinations. ${ }^{3-11)}$ Yoon, et al. ${ }^{7)}$ developed a new method of endoscopic thyroidectomy via a gasless transaxillary approach (TA). This approach offers good magnified surgical view, handling of instruments, and cosmetic results. Therefore, endoscopic and robotic thyroidectomies via the gasless TA have been the most extensively used procedures worldwide. $^{11,12)}$

However, the invasiveness of the gasless TA has been constantly debated, because the flap elevated in this approach is much bigger than that used in conventional open thyroidectomy. ${ }^{13-16)}$ To cope with these critical limitations, we introduced a novel endoscopic thyroidectomy technique via a unilateral axillo-breast approach (UABA) with gas insufflation. ${ }^{10)}$ This approach provides good surgical view and instrument handling similar to those afforded by the gasless TA, but is less invasive because of the smaller workspace created by $\mathrm{CO}_{2}$ gas insufflation.

Many studies have compared the gasless TA with conventional open thyroidectomy or the gasless transaxillary robotic approach. ${ }^{16,17-20)}$ However, no single-center study has compared the gasless TA and other newly developed approaches with respect to reduced invasiveness.

The aim of this study was to evaluate and compare the early surgical outcomes between the UABA with gas and gasless TA for endoscopic thyroidectomy, and to determine whether the UABA with gas is superior to the gasless TA in terms of invasiveness.

\section{Subjects and Method}

\section{Patients}

We enrolled 279 patients who underwent endoscopic thyroid lobectomy via the gasless TA or the UABA with gas at the Department of Otolaryngology between March 2008 and August 2012. The surgeries were performed by three surgeons with extensive experiences and expertise in the thyroid surgery. The surgical approaches were applied differently depending on the period. Out of 279 patients, 84 underwent endoscopic lobectomy via a gasless TA since March 2008, and 195 via a UABA with gas since February 2011. Randomization was not conducted because we did not intend to compare each approach.

All patients were diagnosed as having benign or malignant thyroid tumors by preoperative fine-needle aspiration cytology with ultrasonography. Physical and neurologic examina- tions, including laryngoscopy and computed tomography of the neck, were performed. All female patients also underwent a breast ultrasonography to detect breast masses.

The eligibility criteria for endoscopic thyroid lobectomy were the presence of a benign thyroid tumor measuring less than $5 \mathrm{~cm}$ in diameter or a single, small $(<2 \mathrm{~cm})$, intrathyroidal papillary thyroid carcinoma with no regional and distant metastasis on preoperative imaging studies. The patients with a definite extrathyroidal extension, central or lateral neck lymph node metastasis, distant metastasis, history of previous neck surgery or radiation therapy, severe Graves' disease, and lesion close to the trachea, esophagus, or recurrent laryngeal nerve were excluded. Indications for lobectomy were consistent with the American Thyroid Association guidelines. ${ }^{21)}$

All patients were given oral acetaminophen for pain control after surgery for 1 week in a regular dose.

Informed consent was obtained from all patients after a thorough explanation concerning the disease, surgical procedures, possible complications, and possibility of conversion from endoscopic to open thyroidectomy. The Institutional Review Board of the Korea Cancer Center Hospital approved this study.

\section{Surgical techniques}

The original operative techniques of the gasless TA and UABA with gas have been described in previous publications. ${ }^{7,10)}$ We applied a modified technique for the gasless TA introduced by Koh, et al. ${ }^{9)}$ The only difference from the original technique was a change in the chest wall incision to the superior circumareolar incision to minimize chest scar. The summaries of each approach are as follows.

The position was identical for both approaches. Under general anesthesia, the patient was placed in the supine position with a slight neck extension. The lesion side arm was raised naturally under the range of shoulder motion to avoid brachial plexus injury. The arm was then fixed to achieve the shortest distance between the axilla and thyroid gland.

\section{Gasless TA}

After usual preparation and draping, a 5- to 6-cm vertical skin incision was made in the axillary fossa. A subplatysmal skin flap was elevated off the pectoralis major fascia from the axilla through the sternocleidomastoid muscle (SCM) bifurcation. An external retractor (Meditech Inframed, Seoul, Korea) was used to elevate the sternal head of the SCM and strap muscles until the isthmus of the thyroid was visualized 

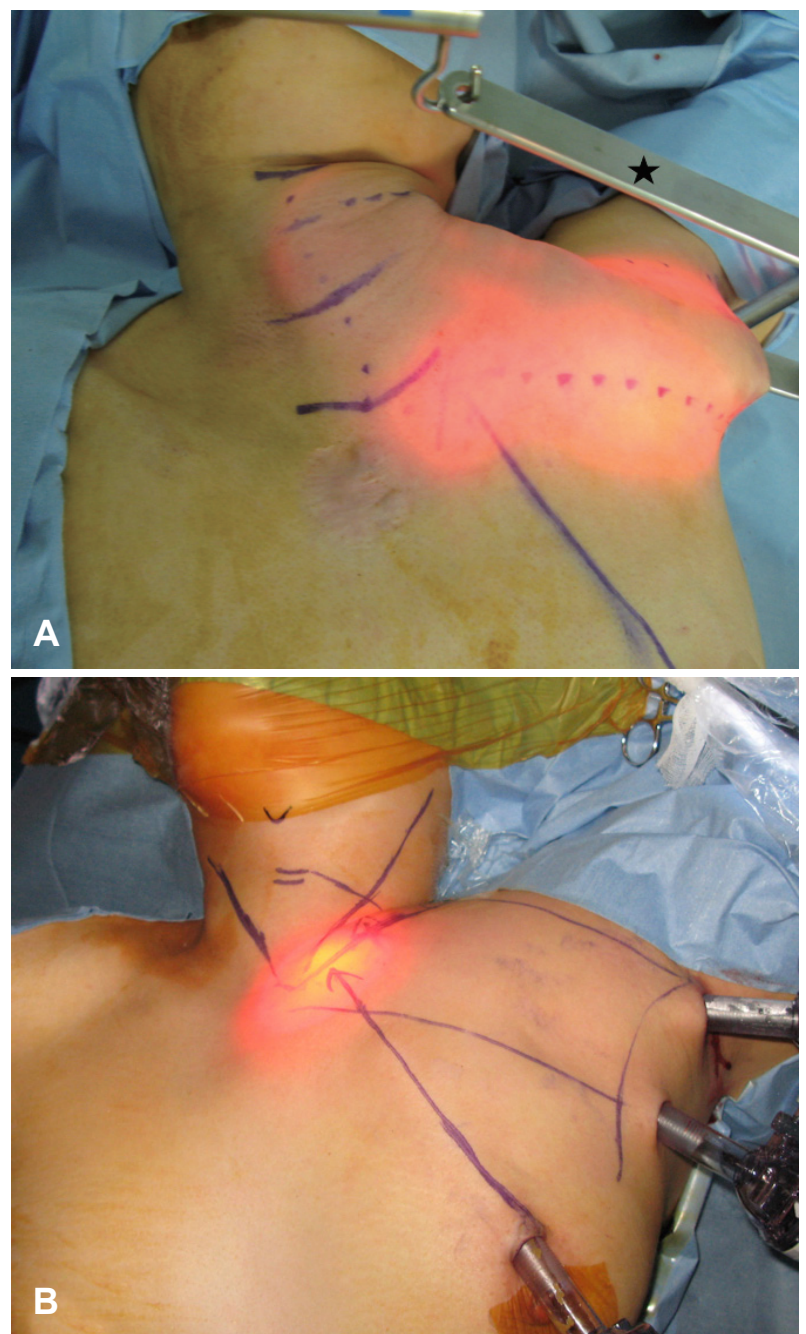

Fig. 1. External view of the gasless transaxillary approach (A) and the unilateral axillo-breast approach with gas (B). During the gasless transaxillary approach, an external retractor (star) is applied for lifting the flap up and maintaining the workspace, so the workspace (reddish illuminated area) is large (A). During the unilateral axillo-breast approach with gas, three trocars are used for operation and workspace (reddish illuminated area) is relatively small (B).

(Fig. 1A). After setting up the external retractor to maintain sufficient workspace, a second skin incision was made on the ipsilateral circumareolar margin of the breast in order to place the trocar for the endoscopic instruments or Harmonic ace (Johnson \& Johnson Medical, Cincinnati, OH, USA). Under the direct visual guidance of a $10-\mathrm{mm}, 30^{\circ}$ rigid endoscope inserted through the upper part of the axillary vertical incision, the operator began the dissection with an endoscopic dissector or a Harmonic ace through the axillary incision and circumareolar port. First, we usually identified the trachea and the inferior pole of the thyroid gland because we thought that the trachea was the single most important land-

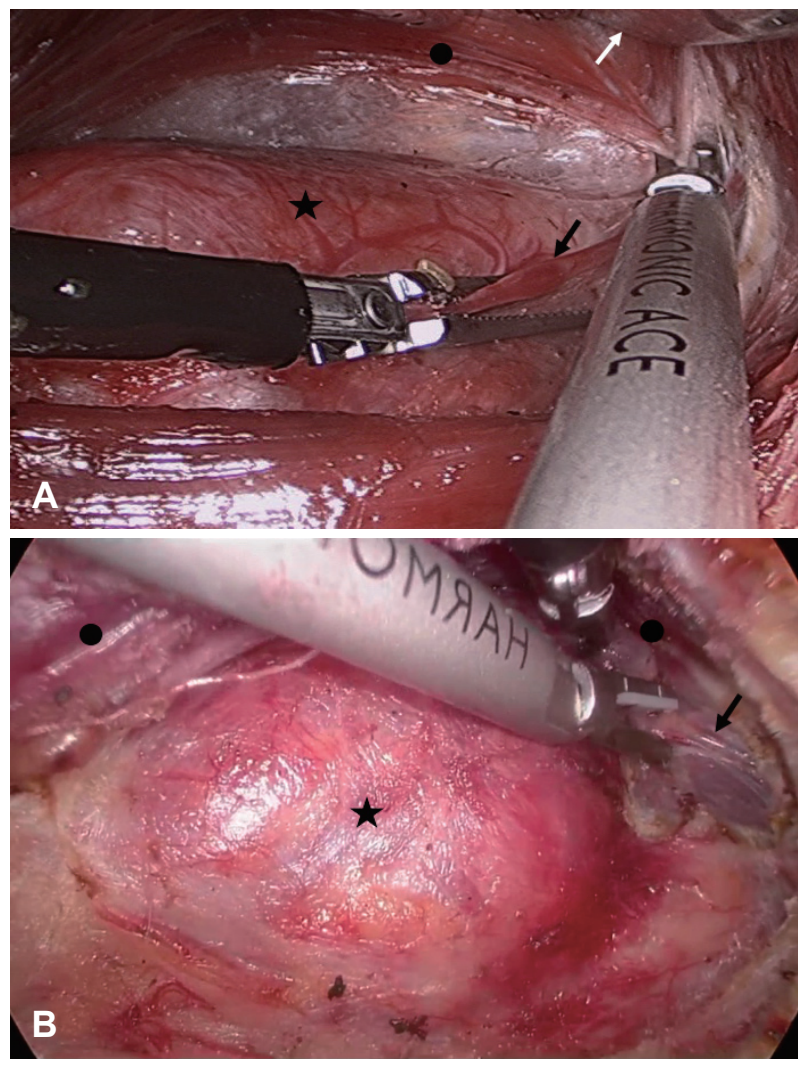

Fig. 2. Intraoperative view of the gasless transaxillary approach (A) and the unilateral axillo-breast approach with gas (B). Left thyroid lobe (star) is seen. Endoscopic forceps are used to grasp the left superior thyroid vessels (black arrow). During operation, an external retractor (white arrow) is applied for lifting the flap including strap muscle (black circle) up to maintain the workspace (A). Left thyroid lobe (star) is seen. Left superior thyroid vessels (arrow) are cut while endoscopic forceps retract the strap muscle (black circles). Contrary to the gasless transaxillary approach, $\mathrm{CO}_{2}$ insufflation is used for maintaining the workspace during whole procedures instead of an external retractor (B).

mark for thyroidectomy. After dividing the inferior thyroid artery and vein, the recurrent laryngeal nerve and inferior parathyroid gland were identified and preserved. During the whole procedure near the recurrent laryngeal nerve, meticulous care was taken not to damage the recurrent laryngeal nerve with the heat from the Harmonic ace.

Next, we divided the superior thyroid vessels close to the upper pole taking care not to injure the external branch of the superior laryngeal nerve (Fig. 2A). The superior parathyroid gland was identified and saved during the dissection of the upper pole. After dissecting the upper and lower parts of the thyroid gland, we severed the Berry ligament taking care to prevent thermal injury to the recurrent laryngeal nerve from the Harmonic ace.

Finally, we dissected the thyroid gland off the trachea and resected the isthmus. The operative specimen was delivered 
through the axillary incision. After antiadhesive material and a suction drain were inserted, the skin was sutured and a surgical brassiere was applied to compress the skin flap.

\section{UABA with gas}

Three 10-mm skin incisions were used for this approach (Fig. 1B). Initially, a 10-mm skin incision was placed in the axillary crease $1 \mathrm{~cm}$ posterior to the anterior axillary line. Another 10-mm incision was made $6 \mathrm{~cm}$ below the first incision. Two 12-mm trocars were inserted through each incision onto the suprafascial plane of the pectoralis major muscle and approached toward the midpoint of the clavicle. With $\mathrm{CO}_{2}$ gas insufflated at a pressure of 5 to $8 \mathrm{~mm} \mathrm{Hg}$, we made a workspace around the clavicle to the SCM with a vascular tunneller and a Harmonic ace. The final 10-mm incision was made in the ipsilateral circumareolar area of the breast. Under the guidance of a $0^{\circ}$ or $30^{\circ}$ rigid endoscope inserted via the upper axillary port, we operated using a Harmonic ace and endoscopic dissector through the lower axillary and breast ports. We started the dissection through the space between the sternal and clavicular heads of the SCM. In this space, we usually dissected the omohyoid muscle for enough exposure of the upper pole. After performing the dissection between the sternothyroid muscle and internal jugular vein, we identified the thyroid gland. The following procedures were almost identical to those of the gasless TA except that no external retractor was needed to maintain the workspace (Fig. 2B). In contrast, UABA with gas used $\mathrm{CO}_{2}$ gas to maintain the workspace. The resected lobectomy specimen was placed in a plastic bag and extracted through the upper axillary port. Similar to the gasless TA, antiadhesive material and a suction drain were inserted into the workspace. The three 10-mm skin incisions were closed using 4-0 absorbable monofilament sutures, and a surgical brassiere was applied for compression.

\section{Outcomes}

We retrospectively evaluated and compared the following variables between the two study groups: clinical characteristics, tumor size, pathologic type, operating time, total amount of drainage for 3 consecutive days (from operation day to postoperative day 2), duration of drainage, duration of postoperative hospital stay, and postoperative complications. As for the duration of drainage, we retained the drain until the drainage for 24 hours measured less than $30 \mathrm{~mL}$. An examination of vocal cord mobility with flexible laryngoscopy was performed to evaluate the presence of vocal cord paralysis preoperatively and 1 day postoperatively in all patients. Permanent vocal cord palsy was diagnosed when no recovery was identified within 6 months. Postoperative pain was evaluated using a Visual Analogue Scale (VAS) at 1 day, 3 days, and 1 month postoperatively. Subjective pain intensity was graded as 0 (no pain), 1 (very slight), 2 (slight), 3 (moderate), 4 (moderately severe), or 5 (severe). We evaluated the subjective satisfaction with cosmetic results by using a VAS at 1 and 3 months postoperatively. The VAS scores for cosmetic satisfaction ranged from 1 to 5 (very dissatisfied, dissatisfied, average, satisfied, and very satisfied, respectively).

\section{Statistical analysis}

All statistical analyses were performed using SPSS for Windows/Macintosh, Version 14.0 (SPSS Inc., Chicago, IL, USA). Data were represented as mean \pm standard deviation, proportions, and/or absolute numbers. Chi-square tests or Fisher's exact tests were used to compare categorical variables, and a t-test was used to compare continuous variables between the two groups. A $p$ value less than 0.05 was considered statistically significant.

\section{Results}

The clinical and pathological characteristics of the patients are summarized in Table 1. Of the 279 patients, 195 (69.9\%) underwent UABA with gas and 84 (30.1\%) underwent the gasless TA. The mean ages and sex proportion showed no statistical differences between the two groups. The mean primary tumor diameter was $8.32 \pm 8.23 \mathrm{~mm}$ in the UABA with gas group and $9.34 \pm 7.09 \mathrm{~mm}$ in the gasless TA group. The malignant lesions in the UABA with gas group comprised 168 papillary thyroid cancers $(86.1 \%)$ and four follicular thyroid cancers $(2.1 \%)$. The malignant lesions in the gasless TA group comprised 71 papillary thyroid cancers $(84.5 \%)$ and two follicular thyroid cancers (2.4\%). There were $23(11.8 \%)$ benign lesions in the UABA with gas group and 11 (13.1\%) in the gasless TA group. The extrathyroidal extensions were found in $23.1 \%$ of patients in the UABA with gas group and $30.9 \%$ of patients in the gasless TA group. We did not do additional immediate treatment even if pathology reports indicated that extrathyroidal extensions were found. Thyroiditis was found in $24.6 \%$ of patients in the UABA with gas group and $34.5 \%$ of patients in the gasless TA group. Mean followup periods were $18.43 \pm 8.12$ months in the UABA with gas 
Table 1. Clinicopathologic characteristics of the patients in the UABA with gas and the gasless TA groups

\begin{tabular}{|c|c|c|c|}
\hline & UABA with gas & Gasless TA & $p$ value \\
\hline No. of patient & $195(69.9 \%)$ & $84(30.1 \%)$ & \\
\hline Mean age & $39.96 \pm 9.47^{*}$ & $40.02 \pm 10.01^{*}$ & 0.959 \\
\hline Female:male & $183: 12$ & $81: 3$ & 0.380 \\
\hline Pathology & & & 0.807 \\
\hline Papillary thyroid cancer & $168(86.1 \%)$ & $71(84.5 \%)$ & \\
\hline Follicular thyroid cancer & $4(2.1 \%)$ & $2(2.4 \%)$ & \\
\hline Benign & $23(11.8 \%)$ & $11(13.1 \%)$ & \\
\hline Tumor size, $\mathrm{mm}$ & $8.32 \pm 8.23^{*}$ & $9.34 \pm 7.09 *$ & 0.327 \\
\hline Extrathyroidal extension & $45(23.1 \%)$ & $26(30.9 \%)$ & 0.073 \\
\hline Thyroiditis & $48(24.6 \%)$ & $29(34.5 \%)$ & 0.089 \\
\hline Follow-up periods (months) & $18.43 \pm 8.12$ & $32.13 \pm 13.84$ & \\
\hline Recurrence & $2(1.0 \%)$ & $1(1.2 \%)$ & 0.094 \\
\hline
\end{tabular}

*values are mean \pm standard deviation. UABA: unilateral axillo-breast approach, TA: transaxillary approach

Table 2. Surgical outcomes in the UABA with gas and the gasless TA groups

\begin{tabular}{lccr} 
& UABA with gas $(\mathrm{n}=195)$ & Gasless TA $(\mathrm{n}=84)$ & $\mathrm{p}$ \\
\hline Operation time $(\mathrm{min})$ & $131.76 \pm 44.37$ & $191.01 \pm 55.90$ & $<0.001$ \\
Pain score POD\# 1 & $2.61 \pm 0.96$ & $3.12 \pm 1.02$ & $<0.001$ \\
Pain score POD\#3 & $1.85 \pm 0.79$ & $2.17 \pm 0.76$ & 0.020 \\
Duration of drain (days) & $3.81 \pm 1.48$ & $4.63 \pm 1.21$ & $<0.001$ \\
Amount of drain (mL) & $142.57 \pm 51.87$ & $168.66 \pm 66.53$ & $<0.001$ \\
Hospital stay (days) & $5.89 \pm 3.02$ & $6.55 \pm 2.20$ & 0.074 \\
\hline
\end{tabular}

UABA: unilateral axillo-breast approach, TA: transaxillary approach, POD: postoperative day

Table 3. Postoperative complications in the UABA with gas and the gasless TA groups

\begin{tabular}{lccc}
\hline & $\begin{array}{c}\text { UABA with gas } \\
(\mathrm{n}=195)\end{array}$ & $\begin{array}{c}\text { Gasless TA } \\
(\mathrm{n}=84)\end{array}$ & $\mathrm{p}$ \\
\hline Transient VCP & $17(8.7 \%)$ & $12(14.3 \%)$ & 0.253 \\
Permanent VCP & $3(1.5 \%)$ & $2(2.4 \%)$ & 0.627 \\
Seroma on the chest & $2(1.0 \%)$ & $7(8.3 \%)$ & 0.002 \\
Bleeding/hematoma & $0(0 \%)$ & $1(1.2 \%)$ & 0.127 \\
Wound infection & $0(0 \%)$ & $0(0 \%)$ & 1.000 \\
\hline
\end{tabular}

UABA: unilateral axillo-breast approach, TA: transaxillary approach, VCP: vocal cord paralysis

group and $32.13 \pm 13.84$ months in the gasless TA group. During follow-up period, we identified 2 cases of recurrence $(1.0 \%)$ in the UABA with gas group and 1 case $(1.2 \%)$ in the gasless TA group. None of the clinicopathologic variables showed significant intergroup differences.

The surgical outcomes are presented in Table 2. The mean operation time was significantly shorter in the UABA with gas group (131.76 $\pm 44.37 \mathrm{~min})$ than in the gasless TA group (191.01 \pm $55.90 \mathrm{~min})(p<0.001)$. The mean postoperative pain VAS scores at 1 and 3 days after surgery were $2.61 \pm 0.96$ and $1.85 \pm 0.79$, respectively, in the UABA with gas group and $3.12 \pm 1.02$ and $2.17 \pm 0.76$, respectively, in the gasless TA group. The VAS scores were significantly lower in the UABA with
Table 4. Cosmetic Satisfaction in UABA with gas and the gasless TA groups

\begin{tabular}{lccc}
\hline Cosmetic satisfaction & $\begin{array}{c}\text { UABA with gas } \\
(n=195)\end{array}$ & $\begin{array}{c}\text { Gasless TA } \\
(n=84)\end{array}$ & $p$ \\
\hline Postoperative 1 month & $4.57 \pm 0.57$ & $4.09 \pm 0.67$ & $<0.001$ \\
Postoperative 3 months & $4.38 \pm 0.98$ & $3.97 \pm 1.27$ & 0.012 \\
\hline All values in the table are mean \pm standard deviation. UABA: \\
unilateral axillo-breast approach, TA: transaxillary approach
\end{tabular}

gas group than in the gasless TA group in the early postoperative period.

The duration of postoperative drainage was also significantly shorter in the UABA with gas group (3.81 \pm 1.48 days) than in the gasless TA group $(4.63 \pm 1.21$ days $)(p<0.001)$.

The cumulative total amounts of drainage for 3 consecutive days were significantly lower in the UABA with gas group $(142.57 \pm 51.87 \mathrm{~mL})$ than in the gasless TA group (168.66 \pm $66.53 \mathrm{~mL})(p<0.001)$. The mean postoperative hospital stay was shorter in the UABA with gas group (5.89 \pm 3.02 days) than in the gasless TA $(6.55 \pm 2.20$ days), but the difference was not statistically significant ( $p=0.074)$.

Postoperative complications were compared between the two groups (Table 3). Transient and permanent vocal cord paralysis occurred less frequently in the UABA with gas group $(8.7 \%$ and $1.5 \%$, respectively) than in the gasless TA group $(14.3 \%$ 
and $2.4 \%$, respectively), but without statistical differences.

The incidence of postoperative seroma was lower in the UABA with gas group (1.0\%) than in the gasless TA group $(8.3 \%)(p=0.002)$. Postoperative bleeding occurred in one patient in the gasless TA group. However, no patients in either group experienced wound infection or conversion to the open approach.

Cosmetic satisfaction scores were excellent in both groups and significantly higher in the UABA with gas group than in the gasless TA group at 1 and 3 months postoperatively (Table 4).

\section{Discussion}

The present study documented our experiences with two techniques of endoscopic thyroidectomy and compared the surgical outcomes of these two approaches in terms of invasiveness.

The incidence of thyroid disease has been increasing, especially among women. ${ }^{22)}$ Female patients are interested not only in the results of treatment but also in the appearance of the postoperative neck scar. Furthermore, female patients are concerned about postoperative pain and quick return to everyday life and job because differentiated thyroid cancer has an excellent prognosis. To satisfy these patient needs and overcome their concerns, many surgical approaches have been introduced. Among those approaches, the gasless TA is an outstanding and representative approach for thyroid surgery. Many institutions worldwide have adopted and practiced this approach for thyroidectomy. ${ }^{11,12,23,24)}$ This approach does not leave a scar around the neck because skin incisions are made in the axillary and circumareolar areas far from the

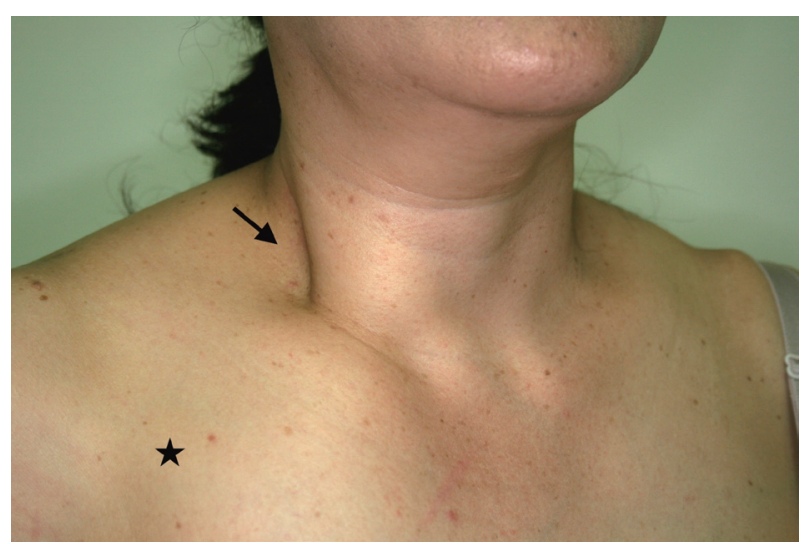

Fig. 3. Postoperative complications after the gasless transaxillary approach. This patient suffered from a seroma in the right chest (star), and a muscle and soft tissue fibrosis in the right neck (arrow) after right thyroid lobectomy via the gasless transaxillary approach. thyroid. However, this increases the distance between the incision site and operation field, consequently requiring inevitable larger flap elevation, longer operation time, more pain, longer hospital stay, and more patient discomfort because of the invasiveness of the procedure. Therefore, some patients experience seroma, upper chest and neck pain, numbness, and soft-tissue or muscle fibrosis (Fig. 3). ${ }^{15,16)}$

We started performing endoscopic thyroidectomy via a gasless TA in 2008. After we experienced some complications because of the invasiveness of the procedure, we devised the UABA with gas in 2011. ${ }^{10)}$ This newly devised UABA with gas provides good surgical view and instrument handling similar to the gasless TA. However, this approach does not require flap elevation from the axilla to the surgical field because gas insufflation through the trocar replaces the flap elevation. Hence, some surgeons call our UABA with gas as the gas TA. These characteristics make the UABA with gas less invasive than the gasless TA. Although there are no clear definitions or criteria for invasiveness of a surgery, certain procedures that require long skin incisions, large flap elevation, and long operation time, and produce many postoperative complications including pain, are commonly considered invasive. In this study, we tried to investigate the superiority of the UABA with gas over the gasless TA in terms of invasiveness. To the best of our knowledge, this is the first study to compare the gasless TA and modified TA using gas insufflation.

No significant differences were observed between the two approaches in demographic (sex, age, etc.) and pathologic data because the indications for both approaches were identical (Table 1).

With respect to surgical outcomes, the UABA with gas had a shorter operation time than did the gasless TA (Table 2). This was because the surgeon performing the UABA with gas need not elevate the flap between the incision site and surgical field, and has to close only $1 \mathrm{~cm}$-sized skin incisions in the axillary and periareolar areas. Shortened operation time is an important factor in decreasing the invasiveness of an approach.

In addition, the pain at postoperative days 1 and 3, duration of drainage, and the total amount of drainage for 3 consecutive days postoperatively were lesser or shorter in the UABA with gas group than in the gasless TA group (Table 2). We assume these features could be attributed to the smaller flap and workspace, and shorter operation time in the UABA with gas. We expect this may encourage surgeons and patients to choose the UABA with gas for thyroidectomy instead of the gasless 
TA, because the majority of patients are anxious about postoperative pain and recovery.

Interestingly, no intergroup difference in hospital stay was observed even though the patients who underwent the UABA with gas showed less pain and shorter duration of drainage. In South Korea, patients tend to stay longer at the hospital because of relatively generous public and private health insurance policies. If there were stricter rules regarding hospital discharge and health insurance, it is certain that patients in the UABA with gas group would leave the hospital sooner.

In terms of the safety of these surgical approaches, the rates of complications such as vocal cord palsy, bleeding/hematoma, and wound infection were not statistically different between the two groups (Table 3). We presume this is because the surgical view and manipulation of endoscopic instruments are identical in both procedures (Fig. 2). However, the incidence of seroma was higher in the gasless TA group than in the UABA with gas group (Fig. 3). We think that more extensive tissue damage from the long and wide flap over the chest, and the rigid retraction applied with an external retractor throughout the surgery in the gasless TA could account for the seroma. Although seroma is not a fatal or serious complication, it can prolong hospital stay and annoy the patients through repeated aspiration and compression. In contrast, in the UABA with gas, trocars are used to create the workspace instead of invasive flap elevation, so the incidence of seroma was none.

Between the two endoscopic approaches, the UABA with gas was significantly superior to the gasless TA in helping pa-

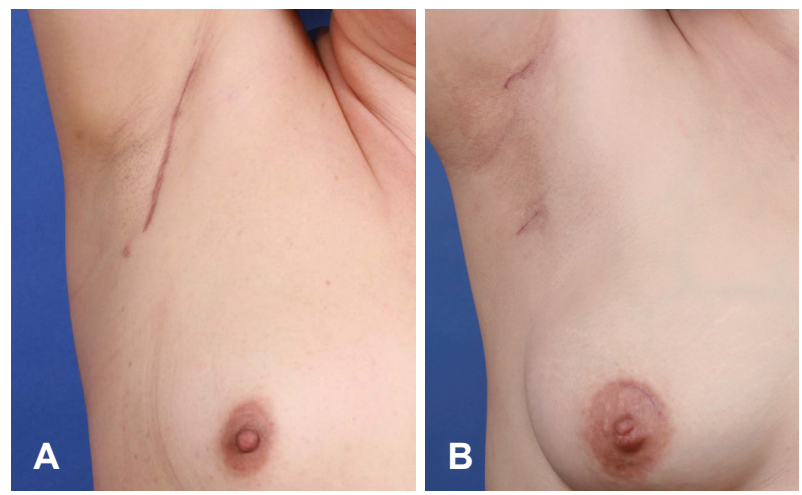

Fig. 4. Postoperative scars of the gasless transaxillary approach (A) and the unilateral axillo-breast approach with gas (B). The gasless transaxillary approach results in a vertical long incision scar in the axilla for a large flap and a small scar in the circumareolar area (A). The unilateral axillo-breast approach with gas leaves three small scars in the axilla and circumareolar area for trocar insertion. Cosmetic result of the unilateral axillo-breast approach with gas is better than that of the gasless transaxillary approach (B). tients achieve cosmetic satisfaction (Table 4). The unilateral axillary scar from the gasless TA, which is vertically oriented and approximately 5 to $6 \mathrm{~cm}$ long, can be conspicuous, especially when the patient is wearing sleeveless clothes and swimsuits (Fig. 4A). However, the two small unilateral incisions in the UABA with gas are not so noticeable (Fig. 4B). Besides, the small upper incision becomes inconspicuous after 1 or 2 months, because it is hidden in the axillary crease.

A limitation of this study is its retrospective design. It was inevitable because we have not performed the gasless TA since we devised the UABA with gas. Therefore, our considerable experience with the gasless TA could have biased the results, because the experience gained would have enabled the surgeons to better perform the UABA with gas. However, even though the experience of performing the gasless TA could be helpful because the surgical view and instrumentation during the main procedure are similar, the approach to the surgical field with a trocar, use of $\mathrm{CO}_{2}$ gas, delivery of specimen, closure of skin incision, and etc., are completely new procedures in the UABA with gas. Therefore, we think that the better outcomes of the UABA with gas are not entirely derived from the experience gained by performing many surgeries via the gasless TA.

In summary, the UABA with gas and gasless TA showed similarities in clinicopathologic characteristics and most complication rates. However, in terms of invasiveness, including operation time, postoperative pain, and duration and amount of drainage, the UABA with gas showed better results than did the gasless TA.

In conclusion, the current study evaluated and compared the early surgical outcomes between the UABA with gas and gasless TA for endoscopic thyroidectomy, and determined that the UABA with gas is superior to the gasless TA in terms of invasiveness. This research may help thyroid surgeons performing endoscopic thyroidectomy choose between the UABA with gas and gasless TA.

\section{REFERENCES}

1) Gagner M. Endoscopic subtotal parathyroidectomy in patients with primary hyperparathyroidism. Br J Surg 1996;83(6):875.

2) Hüscher CS, Chiodini S, Napolitano C, Recher A. Endoscopic right thyroid lobectomy. Surg Endosc 1997;11(8):877.

3) Ohgami M, Ishii S, Arisawa Y, Ohmori T, Noga K, Furukawa T, et al. Scarless endoscopic thyroidectomy: breast approach for better cosmesis. Surg Laparosc Endosc Percutan Tech 2000;10(1):1-4.

4) Miccoli P, Bellantone R, Mourad M, Walz M, Raffaelli M, Berti P. Minimally invasive video-assisted thyroidectomy: multiinstitutional experience. World J Surg 2002;26(8):972-5.

5) Park YL, Han WK, Bae WG. 100 cases of endoscopic thyroidectomy: 
breast approach. Surg Laparosc Endosc Percutan Tech 2003;13(1): $20-5$.

6) Shimazu K, Shiba E, Tamaki Y, Takiguchi S, Taniguchi E, Ohashi S, et al. Endoscopic thyroid surgery through the axillo-bilateral-breast approach. Surg Laparosc Endosc Percutan Tech 2003;13(3):196-201.

7) Yoon JH, Park CH, Chung WY. Gasless endoscopic thyroidectomy via an axillary approach: experience of 30 cases. Surg Laparosc Endosc Percutan Tech 2006;16(4):226-31.

8) Choe JH, Kim SW, Chung KW, Park KS, Han W, Noh DY, et al. Endoscopic thyroidectomy using a new bilateral axillo-breast approach. World J Surg 2007;31(3):601-6.

9) Koh YW, Kim JW, Lee SW, Choi EC. Endoscopic thyroidectomy via a unilateral axillo-breast approach without gas insufflation for unilateral benign thyroid lesions. Surg Endosc 2009;23(9):2053-60.

10) Lee MC, Mo JA, Choi IJ, Lee BC, Lee GH. New endoscopic thyroidectomy via a unilateral axillo-breast approach with gas insufflation: preliminary report. Head Neck 2013;35(4):471-6.

11) Hakim Darail NA, Lee SH, Kang SW, Jeong JJ, Nam KH, Chung WY. Gasless transaxillary endoscopic thyroidectomy: a decade on. Surg Laparosc Endosc Percutan Tech 2014;24(6):e211-5.

12) Lee J, Chung WY. Robotic thyroidectomy and neck dissection: past, present, and future. Cancer J 2013;19(2):151-61.

13) Tan CT, Cheah WK, Delbridge L. "Scarless" (in the neck) endoscopic thyroidectomy (SET): an evidence-based review of published techniques. World J Surg 2008;32(7):1349-57.

14) Inabnet WB 3rd. Robotic thyroidectomy: must we drive a luxury sedan to arrive at our destination safely? Thyroid 2012;22(10):988-90.

15) Patel D, Kebebew E. Pros and cons of robotic transaxillary thyroidectomy. Thyroid 2012;22(10):984-5.

16) Landry CS, Grubbs EG, Warneke CL, Ormond M, Chua C, Lee JE, et al. Robot-assisted transaxillary thyroid surgery in the United States: is it comparable to open thyroid lobectomy? Ann Surg Oncol 2012; 19(4):1269-74.

17) Jeong JJ, Kang SW, Yun JS, Sung TY, Lee SC, Lee YS, et al. Comparative study of endoscopic thyroidectomy versus conventional open thyroidectomy in papillary thyroid microcarcinoma (PTMC) patients. J Surg Oncol 2009;100(6):477-80.

18) Lang BH, Chow MP. A comparison of surgical outcomes between endoscopic and robotically assisted thyroidectomy: the authors' initial experience. Surg Endosc 2011;25(5):1617-23.

19) Lee J, Lee JH, Nah KY, Soh EY, Chung WY. Comparison of endoscopic and robotic thyroidectomy. Ann Surg Oncol 2011;18(5):1439-46.

20) Tae K, Ji YB, Jeong JH, Kim KR, Choi WH, Ahn YH. Comparative study of robotic versus endoscopic thyroidectomy by a gasless unilateral axillo-breast or axillary approach. Head Neck 2013;35(4):477-84.

21) American Thyroid Association (ATA) Guidelines Taskforce on Thyroid Nodules and Differentiated Thyroid Cancer, Cooper DS, Doherty GM, Haugen BR, Kloos RT, Lee SL, et al. Revised American Thyroid Association management guidelines for patients with thyroid nodules and differentiated thyroid cancer. Thyroid 2009;19 (11):1167-214.

22) Siegel R, Naishadham D, Jemal A. Cancer statistics, 2013. CA Cancer J Clin 2013;63(1):11-30.

23) Kandil EH, Noureldine SI, Yao L, Slakey DP. Robotic transaxillary thyroidectomy: an examination of the first one hundred cases. J Am Coll Surg 2012;214(4):558-64; discussion 564-6.

24) Kuppersmith RB, Holsinger FC. Robotic thyroid surgery: an initial experience with North American patients. Laryngoscope 2011;121 (3):521-6. 